com demandas que estão relacionadas aos grandes problemas sociais de nossa civilização.

Relendo o texto lacaniano "A direção do tratamento e os princípios de seu poder" à luz do cenário atual, Serge Cottet tece importantes considerações que têm conseqüências sobre a prática do psicanalista na contemporaneidade. Partindo da constatação de que o futuro da psicanálise previsto por Freud em "Linhas de progresso na terapia psicanalítica" é o nosso presente, isto é, a psicanálise, hoje, está ampliada a contextos e problemáticas que não estavam ao al cance da ação do psicanalista, Serge Cottet nos adverte: há uma abertura do dispositivo, mas a psicanálise não se presta a intervir em qualquer situação.

A extensão da aplicação da psicanálise à terapêutica produz uma variação das práticas, mas não uma degradação, já que seus princípios se mantêm. U ma prática, mesmo em circunstâncias adversas, quando esclarecida por seus princípios, não se degrada, nos lembra Serge Cottet. Ao contrário, o enfraquecimento das regras, em muitos casos, é o que permite o encontro com o real; a clínica tem demonstrado isso. 0 problema concerne em saber qual remanejamento da técnica é necessário para que o ato analítico se produza. Nisso reside a diferença entre a psicanálise aplicada à terapêutica e as psicoterapias: não se trata de escuta e a eficácia não se resume à presença. Banalizar a escuta oferecendo apenas uma presença é lidar com o problema na modalidade do universal. 0 ato analítico, que se dirige ao particular, tem como horizonte, em cada caso, fazer existir o inconsciente. Assim, Cottet faz uma afirmação instigante: a psicanálise lida apenas com exceções.

Cada texto que compõe esta publicação nos remete ao esforço de operar, na clínica psicanalítica a partir da orientação em direção à exceção. Nos dois sentidos que esta palavra pode nos remeter: 0 excessivo e o que escapa à regra. Quer dizer, o real sem lei e que não pode ser classificado nem generalizado. Por mais que 0 dispositivo tenha sofrido variações desde Freud, esse é o principio que orienta o psicanalista.

Verificar a forma que o sintoma, como signo do real, aparece em nossos tempos e obter efeitos terapêuticos a partir de sua emergência e não de sua sutura, como fazem os psicoterapeutas, é o convite que este livro nos faz.

Recebido em 27/9/2005.

Aprovado em 17/ 10/ 2005.

M aria José Gontijo Salum

mgontijo.bhe@terra.com.br

\section{ATUALIDADE E PERTINÊNCIA CLÍNICA DO TEXTO DE FREUD}

10 x Freud. Angela C. Bernardes (org.) Rio de Janeiro: Azougue, 2005, 253 p.

\section{Angélica Bastos \\ Psicanalista; professora adjunta no Programa de Pós-graduação em Teoria Psicanalítica da UFRJ}

Numa carta a Ludwig Binswanger, Freud confidenciava sua convicção de ter iniciado algo que ocuparia os homens durante muito tempo, embora às vezes um descontentamento em relação à sua extensão e seu aprofundamento o assaltasse; afinal, não havia nada na estrutura do homem que o predispusesse a se ocupar de psicanálise. 
A psicanálise continua a ocupar os homens porque ela foi mais que um fato na história, e o inconsciente mais que um conceito ou uma idéia; porque, pelo desejo de Freud, ela se fez transmissão.

$10 \times$ Freud, coletânea organizada por Angela Bernardes, reúne dez artigos de psicanalistas, professores do curso de Especialização em Psicanálise e Laço Social da Universidade Federal Fluminense (UFF). Os trabalhos convidam a ler Freud e problematizam seu texto. Mantendo a significação insaturada, o título veicula que não há um Freud em si; sua obra guarda uma potência que 0 autor-leitor multiplica segundo o problema que Ihe endereça.

Cada artigo do livro é convincente quanto ao interesse da mencionada leitura. Uma característica sua, talvez a maior, seja a de traduzir em pertinência clínica a atualidade do texto freudiano. $10 \times$ Freud não se qualifica por adjetivos, mas pelas questões substantivas que coloca.

Em "Freud e a nostalgia do pai", PauIo Vidal relê Totem eTabu e 0 declínio do complexo de Édipo, descobrindo no primeiro um dos nomes do declínio do pai. À complexidade da função paterna - a qual comporta pelo menos dois pais, o edípico e o da horda - é restituído o núcleo vazio: o pai morto como aquele que articula gozo e lei. Da idéia de declínio, que 0 autor distingue da noção de decadência e do conceito psicanalítico de recalque, deriva-se a falha estrutural do pai, bem como indicações clínicas relativas à direção e ao fim das análises.

Com um sonho, Letícia Balbi introduz pela via régia o inconsciente. "Anotações sobre o conceito de inconsciente desde Freud" confere à transferência sua função de incluir a alteridade, condição indispensável à construção do saber não sabido na análise. A partir do inconscien- te estruturado como uma linguagem, a autora sublinha a participação da alteridade na própria definição do significante. Com Jacques Lacan, 0 artigo desenvolve a transposição da estrutura da linguagem para a fórmula do sujeito suposto saber, por meio da qual se patenteia a inserção do analista no inconsciente.

$\mathrm{Na}$ esfera rarefeita das teorizações sobre os atos, Luís Moreira de Barros lê A psicopatologia da vida cotidiana. "Para além dos atos fal hos" se engaja na formalização da dimensão de ato própria a nossas ações, dando inteligibilidade aos atos em função da outra cena. No ato falho e no ato sintomático, 0 autor destaca, além do sentido singular, sua interpretabilidade. A dimensão significante de todo ato implica alienação e perda, o que confere 0 caráter falho a todos os atos, podendo despertar o sujeito para o inconsciente.

Freud operou um corte com o que era até então possível pensar e fazer, colocando em outras bases temas que desfrutavam de consistência na filosofia. Conforme sustenta Ricardo Sá, enquanto efeito de linguagem a realidade se apresenta como perdida. "A estrutura alucinatória da realidade" devolve a dimensão da perda de realidade ao dispositivo clínico introduzido por Freud com a hipótese do inconsciente. A perda se inscreve pela referência ao vazio de das Ding, que redimensiona o sentido da noção de realidade nos sonhos, na alucinação e, sobretudo, na experiência psicanalítica.

Com Angela Bernardes, o leitor atravessa vários textos freudianos num percurso pautado nas tensões entre a ferocidade do supereu e a satisfação narcísica dos ideais. Em "O eu e o supereu", a autora situa neste último um dos nomes da divisão do sujeito que se traduz em devastação e sentimento de culpa. Da melancolia e da neurose obsessiva às ditas 
depressões neuróticas de nossos dias, a autora salienta a dimensão narcísica do laço a ser rompido no luto. 0 trabalho discute o tratamento (im)possível do supereu na análise, ao mesmo tempo que sustenta a necessidade de uma via adequada a seu manejo clínico.

Em "Considerações sobre o mal-estar na civilização", que não poderia faltar nesse conjunto, Giselle Fal bo retoma uma reflexão ética que mantém vivas as interrogações de Freud diante das tendências enigmáticas da civilização premida entre exigências insensatas de renúncia pulsional e o imperativo de gozo que Ihes é correlato. A autora aponta o caráter estrutural do mal-estar e ressalta a questão da boa distância a ser estabelecida na relação com o próximo.

Maria LídiaAlencar trata a fantasia nos textos freudianos do ponto de vista da diferenciação entre neurose e perversão. 0 artigo "A concepção freudiana da fantasia" percorre uma série de dimensões do objeto e de sua falta, passando pelo falo e pelo fetiche, para depreender a escrita mínima que articula sujeito e objeto na fantasia. A autora situa no além-doprincípio-do-prazer um ponto de inflexão nas concepções de Freud, ponto a partir do qual neurose e perversão se reúnem no campo do gozo e se distinguem pela posição dos sujeitos em relação a ele.

"Freud e as instituições de saúde e ensino" é um trabal ho que extrai as conseqüências de dois artigos de Freud para a extensão da psicanálise. Valmir Sbano discute as "Linhas de progresso na terapia psicanalítica" e "O ensino da psicaná lise nas universidades", revelando um Freud atento aos desafios que 0 analista deveria enfrentar para sustentar nas instituições públicas uma clínica do sujeito. 0 autor mostra também que 0 ensino da psicanálise implica uma experiência do sujeito do inconsciente e que, por isso, dá lugar à transferência, requerendo trabalho do significante para todos os envolvidos nesse ensino.

Com Francisco Leonel Fernandes descobre-se em que medida a operação fundadora de Freud é tributária do aparelho científico, ao mesmo tempo que institui uma região independente. 0 artigo "Psicanálise e ciência" elege o "Projeto", em que detecta uma manobra diferencial, pois, no limite, a incompatibilidade entre o modelo adotado e a experiência clínica culminará no manejo próprio ao campo do inconsciente. A partir dos dois níveis de redução, o discreto das trilhas e 0 continuum dos afetos, é traçado o caminho que levou Freud a consumar com o inconsciente, não um reducionismo, mas o corte, tal como a ciência moderna o opera.

Em "Freud, Marx e a Weltanschauung", Cláudio Oliveira aborda as relações da psicanálise com a ciência e a religião. A preferência de Freud pela W eltanschauung científica em detrimento da religiosa reside na precariedade da primeira frente ao caráter totalizante da segunda. 0 artigo avança com a distinção entre, de um lado, a ciência e, de outro, a psicanálise e o marxismo, que partem ambos do sintoma. Acompanhando o autor, vemos as vicissitudes a que se encontram sujeitos o marxismo e a ação revolucionária, em sua inclinação a uma Weltanschauung religiosa, bem como a distância que os separa do ato analítico.

$\mathrm{N}$ ão é de se negligenciar o impacto do texto de Freud sobre os leitores em geral. O leitor mais circunstancial e o mais prevenido são suscetíveis de sofrer um efeito especial diante dele: sentem-se tocados, mesmo não sabendo por que ou não podendo traduzir em razões e alcançar com a significação esse efeito. $A$ isso 
eu chamaria de transferência e mesmo de 'um efeito de verdade'. 10 x Freud vem participar dessa transferência e desse efeito de verdade.

Recebido em 29/9/2005.

Aprovado em 17/ 10/ 2005.

Angélica Bastos

abastosg@terra.com.br

\section{À PROCURA DO ESTABELECIMENTO DE TRÂNSITO E MOBILIDADE}

Limites. Marta Rezende Cardoso (org.)

São Paulo: Escuta, 2004, 220 p.

\section{Pedro Luiz Ribeiro de Santi \\ Psicanalista; professor de psicologia clínica: teoria psicanalítica, na Cogeae/ PUC-SP e na Faculdade de Comunicação Social da ESPM . É autor de A crítica ao eu na M odernidade. Em M ontaignee Freud (Casa do Psicólogo, 2003), entre outros estudos sobre psicanálise e subjetividade.}

Já faz algum tempo que a clínica e a produção teórica psicanalítica têm sido dominadas pela reflexão sobre os casos-limite. Sua discussão vem de longa data desde os casos difíceis tratados por Ferenczi. Hoje, porém, ela invadiu definitivamente a cena psicanalítica.

Para além de um quadro a mais a ser estudado dentro da psicopatologia psicanalítica, os casos-limite trouxeram uma crise a todo o campo. Da formulação inicial, segundo a qual aqueles pacientes não poderiam ser atendidos de modo adequado no enquadre freudiano, constituiu-se uma nova clínica, com base na escola das relações de objeto.
Contudo, não se trata apenas da descoberta de outras estruturas psicopatológicas a serem incorporadas ao quadro anterior. Todo ele se altera, visivelmente. É muito comum, por exemplo, que pacientes identificados como histéricos na clínica freudiana sejam considerados casos-limite nesta nova clínica.

Com a discussão se estendendo a outras formas de sofrimento mental que chegam cada vez mais aos contextos clínicos (somatizações, adições, distúrbios da ansiedade ou da representação corporal, etc.), o novo paradigma clínico vem se consolidando como aquele capaz de dar conta das novas patologias.

Nada de estranho em se pensar em formas de sofrimento precipitadas por condições contemporâneas de vida. E nada de estranho em se pensar na criação de enquadres de sessão mais adequados, dentro da perspectiva ética e teórica da psicanálise. Estranho é o alarde e a pressa com que se decreta a morte e desinteresse de toda uma tradição psicanalítica: do próprio Freud, passando por autores como Lacan ou Laplanche. Eles não teriam mais nada a nos dizer sobre a clínica contemporânea. Estabelece-se, assim, um limite: fim de um modelo, início de outro radicalmente outro.

Treinada para perceber lapsos, repetições ou omissões, nossa escuta é chamada ante o decreto da morte da clínica freudiana, com seu todo corpo conceitual: sexualidade, recalque, fantasia, inconsciente, realidade psíquica.

Se é mais do que claro que o modelo freudiano não pode dar conta de determinadas formas de sofrimento, é também claro que tal virada de página na história psicanalítica soa sintomática.

A coletânea Limites, de Marta Rezende Cardoso, vem colocar em discussão, de forma original, esta problemática. Se os 